\title{
Electronic system based on PSoC technology and implemented in android platform for the electrochemical characterization of materials through the cyclic voltammetry technique
}

\begin{abstract}
In this review is shown the development of an electronic portable system of electrochemical measurements based on PSoC technology and Android, which characterizes materials across the cyclic voltammetry technique. For the application of the above mentioned technique, it is necessary a potentiostat, this one induces a potential ramp in a substance while obtaining current signals of the substance. The aim of this work is to increase the access to the techniques of electrochemical analysis of materials in educational contexts, considering that the use of a commercial team of these characteristics is limited by factors as its high cost and its big size, which causes its difficult acquisition in some laboratories. With the PSoC technology it was possible to develop a potentiostat inside of a chip, since it contains analogical and digital reconfigurable blocks into it. In this work a Free SoC 2 card was used, which has as a main element PSoC5 ${ }^{\circledR}$ and it was programmed in the software PSoC Creator. Additionally, the design of an Android app is shown, which is capable of connecting via Bluetooth with the $\mathrm{PSoC}$ circuit and graphic the voltage and current answers obtained during the application of the technique.
\end{abstract}

Keywords: PSoC technology, android, cyclic voltammetry, potentiostat
Volume 4 Issue 3 - 2018

\author{
Álvaro Arrieta,' Oscar Fuentes, ${ }^{2}$ Kevin \\ Navas, ${ }^{2}$ Katerine Ballesteros ${ }^{2}$ \\ 'Department of Biology and Chemistry, Universidad de Sucre, \\ Colombia \\ ${ }^{2}$ Universidad Pontificia Bolivariana, Colombia
}

Correspondence: Álvaro Arrieta, Departamento de Biología y Química, Facultad de Educación y Ciencias, Universidad de Sucre, Sincelejo, Colombia, Email alvaro.arrieta@unisucre.edu.co

Received: January 25, 2018 | Published: May 30, 2018

\section{Introduction}

In the industry, many methods to obtain electrochemical information about materials are used. The aim is to characterize electrochemical materials to evaluate their utility in some applications. Nowadays, there are different techniques of electrochemical analysis, which are capable to classify physical chemistry parameters. An usual technique is called cyclic voltammetry, this technique is responsible to set a potential ramp to a sample and to register the current flowing through the material during the electrochemical reaction, the results from this process is a Current vs Voltage graphic called Voltammogram. ${ }^{1}$ The potentiostat is the electrochemical device responsible to apply the cyclic voltammetry technique, through three electrodes, reference electrode, counter electrode and working electrode. The basic circuit of a potentiostat is based on operational amplifier and microprocessors capable to communicate the electrochemical signals to the computer equipment. However there are some sectors where a potentiostat is not sufficient since the physical chemistry analysis is required in situ, thus, was developed a portable electrochemical device based on PSoC and Android technology capable to apply the cyclic voltammetry technique in situ.

\section{Discussion}

PSoC (Programmable System on Chip) is a family of microcontrollers which contains digital and analog blocks on a single chip. ${ }^{1,2-4}$ Thanks to this technology and Android platform was possible to develop a mini-potentiostat device capable to apply the cyclic voltammetry technique and to transmit the signals via bluetooth for the signals processing in Android (Figure 1). The system shown in Figure 1A consists of three stages, "Electrodes", "Circuit based on PSoC" and "Smartphone". Through Electrodes it is obtained the electrochemical information; the Circuit based on PSoC is responsible to apply the voltammetry technique and the Android Application Stage processes and displays the results of cyclic voltammetry. The circuit based on operational amplifiers is shown in Figure 1B, this analog circuit was integrated in the PSoC Chip, and was connect to Android device via bluetooth. A series of tests were applied to verify its correct functioning of the system, applying the technique of different substance of control through the developed potentiostat and commercial equipment (Figure 2). It was proved that the obtain answers with the designed potentiostat, was similar to the acquired response by the commercial potentiostat, which is useful as a reference to develop this prototype. According to this application, the cyclic voltammetry technique could be applied in researches that require the substance analysis in situ. Taking in account that open source technologies are used in this work, it is easier to the scientific community to obtain the proposed device. ${ }^{5}$

\section{Conclusion}

According to result shown in the Figure 2, it is possible to say that the prototype system is capable to characterize materials across cyclic voltammetry technique. Additionally, thanks the Android and $\mathrm{PSoC}$ technology was possible the development of a portable electrochemical device, which it can apply the cyclic voltammetry technique in situ. 
A

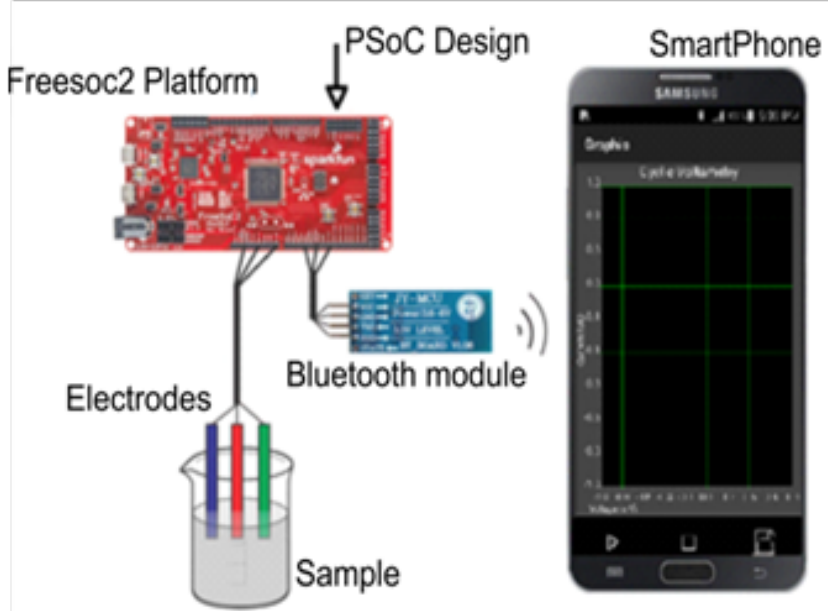

B

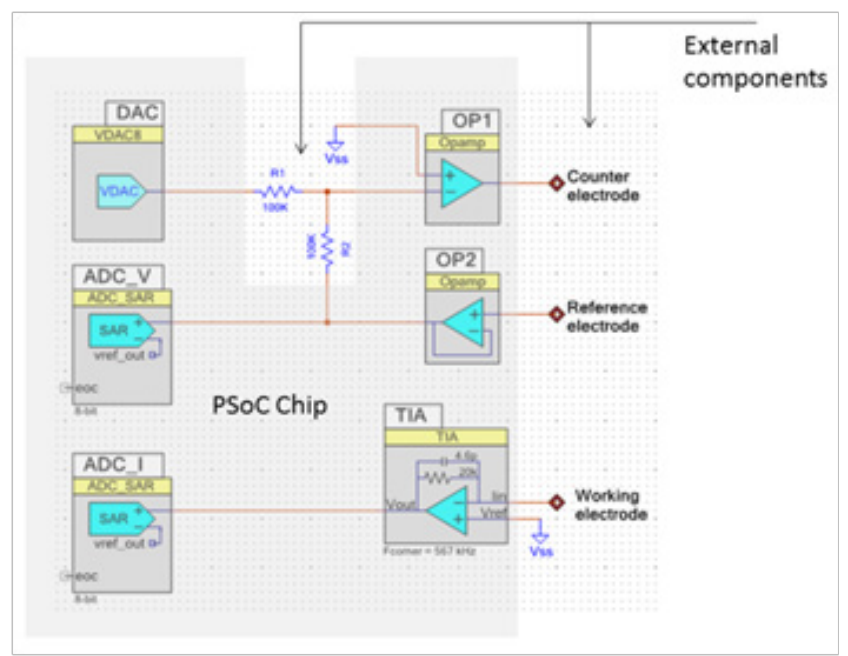

Figure I A) System scheme based on PSoC and Android technology, B) Design on PSoC Chip.
A

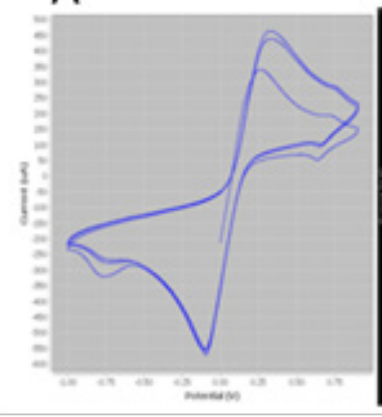

B

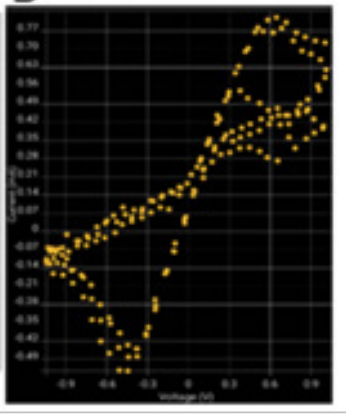

Figure 2 A) Voltammogram of potassium cyanide using commercial potentiostat, B) Voltammogram of potassium cyanide using prototype potentiostat.

\section{Acknowledgements}

We are very grateful to Univeridad Pontificia Bolivariana for all their support.

\section{Conflict of interest}

Authors declare that there is no conflict of interest.

\section{References}

1. Arrieta A, Fuentes O, Palencia M. Android and PSoC Technology Applied to Electronic Tongue Development. Research Journal of Applied Sciences, Engineering and Technology. 2015;10(7):782-788.

2. Mar M, Sullam B, Blom E. An architecture for a configurable mixedsignal device. Solid-State Circuits, IEEE Journal. 2003;38(3):565-568.

3. Cabrera J, Velasco J. Implementación de Filtros Análogos Usando PSoCs/FPAAs. Revista Colombiana de Física. 2008;40(2):399-401.

4. Cabrera J Velasco. Diseño e Implementación de un Sistema Embebido para el Procesamiento de Señales Ultrasónicas. Revista Colombiana de Fsísica. 2011;43(1):100-104.

5. Arrieta A, Jaramillo A, Fuentes $\mathrm{O}$, et al. Síntesis y caracterización de películas conductoras preparadas a partir de almidón de yuca y polipirrol como uso potencial en el desarrollo de un acumulador electroquímico de carg. Puente Revista Cientifica. 2010;8:7-13. 